\title{
POPULASI DAN SERANGAN KUTU PUTIH PEPAYA PARACOCCUS MARGINATUS (HEMIPTERA: PSEUDOCOCCIDAE) PADA TANAMAN PEPAYA DI DAERAH DATARAN RENDAH SUMATERA SELATAN
}

\author{
Rosdah Thalib $^{1,3}$, Rossi Fachrullah Rozi, Triani Adam ${ }^{1}$, Khodijah $^{3,4}$, \& Siti Herlinda ${ }^{1,3}$ \\ ${ }^{1}$ Jurusan Hama dan Penyakit Tumbuhan, Faperta, Universitas Sriwijaya, Indralaya \\ ${ }^{2}$ Mahasiswa Program Studi Agroekoteknologi, Faperta, Universitas Sriwijaya, Indralaya \\ ${ }^{3}$ Pusat Unggulan Riset Pengembangan Lahan Suboptimal(PUR-PLSO), Universitas Sriwijaya, Palembang \\ ${ }^{4}$ Jurusan Hama dan Penyakit Tumbuhan, Faperta, Universitas Palembang, Palembang \\ E-mail: rosdahthalib@yahoo.com
}

\begin{abstract}
Populations and damage by the papaya mealybug Paracoccus marginatus (Hemiptera: Pseudococcidae) on papaya in lowland areas of South Sumatera. One of the main problems in papaya cultivation today is the presence of a newly introduced pest, the white papaya mealybug, Paracoccus marginatus (Hemiptera: Pseudococcidae). This study aimed to observe the mealybug populations and its damage percentage in papaya plants and to identify its host plants in South Sumatera. The study was carried out on the fruit and vegetable producing area in Indralaya, South Sumatera. The survey was conducted on papaya plantation plots with a minimum size of $1000 \mathrm{~m}^{2}$. Data from the observation indicated that populations of $P$. marginatus on papaya fruit were not significantly different to those on papaya leaves, except for the first observation in the rainy season. In general, the percentages of mealybug damages were not affected by the season and the percentages of damage on the leaves were not different from those on the fruits of the papaya plants. Inventory of $P$. marginatus host plants on the area resulted in a total of 12 species of host plants dominated by dicotyledonous plant species. The host plants were from 11 families, i.e. Anacardiaceae, Caricaceae, Cucurbitaceae, Euphorbiaceae, Fabaceae, Myrtaceae, Rosaceae, Rutaceae, Sapindaceae, Sapotaceae, and Solanaceae.
\end{abstract}

Key words: damage, papaya, Paracoccus marginatus, populations

\section{ABSTRAK}

Populasi dan serangan kutu putih pepaya Paracoccus marginatus (Hemiptera: Pseudococcidae) pada tanaman pepaya di daerah dataran rendah Sumatera Selatan. Salah satu masalah utama dalam budidaya tanaman pepaya saat ini adalah serangan hama pendatang baru, yaitu kutu putih pepaya Paracoccus marginatus (Hemiptera: Pseudococcidae). Penelitian ini bertujuan untuk mengamati populasi dan serangan kutu putih pada tanaman pepaya di Sumatera Selatan, dan menginventarisir dan mengidentifikasi tumbuhan inang kutu putih pepaya di Sumatera Selatan. Pengamatan populasi dan serangan dilakukan di sentra produksi buah-buahan dataran rendah dan tinggi di Indralaya, Sumatera Selatan. Survei dilakukan pada areal petak pertanaman pepaya dengan luas minimal $1000 \mathrm{~m}^{2}$. Hasil survei menunjukkan bahwa populasi $P$. marginatus baik pada buah maupun daun pepaya cenderung tidak berbeda nyata kecuali pada pengamatan pertama pada musim hujan. Secara umum persentase serangan $P$. marginatus tidak dipengaruhi musim, demikian juga persentase serangan pada bagian daun tidak berbeda dengan bagian buah tanaman pepaya. Inventarisasi spesies tumbuhan inang hama $P$. marginatuspada lokasi penelitian menghasilkan sebanyak 12 spesies tumbuhan inang yang didominasi oleh jenis tumbuhan dikotil. Tumbuhan inang tersebut berasal dari 11 famili, yaitu Anacardiaceae, Caricaceae, Cucurbitaceae, Euphorbiaceae, Fabaceae, Myrtaceae, Rosaceae, Rutaceae, Sapindaceae, Sapotaceae, dan Solanaceae.

Kata Kunci: Paracoccus marginatus, pepaya, populasi, serangan

\section{PENDAHULUAN}

Salah satu hama penting yang mengganggu produktivitas budidaya pepaya adalah hama kutu putih pepaya, Paracoccus marginatus (Hemiptera:
Pseudococcidae). Hama pendatang baru ini berasal dari Benua Amerika dan diperkirakan masuk ke Indonesia pada tahun 2008 (Rauf, 2009). Serangga hama ini awalnya ditemukan merusak buah, batang, dan daun pepaya di Kebun Raya Bogor, Jawa Barat hingga 
menyebabkan ribuan pohon pepaya menurun produktivitasnya, bahkan banyak menyebabkan kematian pada tanaman muda (Friamsa, 2009). Kutu putih pepaya merupakan serangga polifag yang dapat menyerang banyak spesies tanaman tropika (Muniappan et al., 2008). Selain menyerang tanaman pepaya, kutu putih $P$. marginatus ini dapat menyerang tanaman hias, tumbuhan liar (gulma), dan tanaman hutan (Amarasekare et al., 2008).

Untuk mengatasi permasalahan hama ini perlu alternatif pengendalian yang relatif lebih aman baik bagi musuh alami, petani, produk yang dihasilkan, serta lingkungan sekitarnya. Karena produk buah pepaya merupakan buah yang dikonsumsi segar, maka konsumen menuntut produk tersebut bebas dari residu racun yang membahayakan kesehatan maupun lingkungan. Pengendalian yang relatif aman adalah pengendalian hama terpadu (PHT) yang memerlukan informasi biologi dan ekologi hama yang akan dikendalikan. Mengingat informasi biologi dan serangan hamakutu putih pepaya di Sumatera Selatan belum banyak diteliti dan dipublikasikan, penelitian ini dilaksanakan dengan tujuan: (1) mengamati dan menduga tingkat populasi dan serangan kutu putih pada tanaman pepaya di Sumatera Selatan, dan (2) menginventarisir dan mengidentifikasi jenis-jenis tumbuhan inang hama kutu putih di Sumatera Selatan.

\section{METODE PENELITIAN}

Tempat dan Waktu. Penelitian pengamatan populasi P. marginatus dilakukan di sentra tanaman buah pepaya dataran rendah, yaitu di daerah Indralaya,Sumatera Selatan, yang dimulai bulan Maret hingga September 2013.

Pengamatan Populasi Kutu Putih Pepaya, $P$. marginatus. Pengamatan populasi $P$. marginatus dilakukan di sentra tanaman buah pepaya dataran rendah, yaitu di daerah Indralaya,Sumatera Selatan, yang dimulai sejak Maret hingga September 2013.Survei dilaksanakan pada petak pertanaman pepaya dengan luas minimal $1000 \mathrm{~m}^{2}$.Tanaman pepaya yang dipilih adalah tanaman yang mulai memasuki fase generatif. Petak pengamatan dibagi menjadi lima subpetak (lima subpetak = lima ulangan) fase vegetatif dan lima subpetak fase generatif, masing-masing subpetak seluas $100 \mathrm{~m}^{2}$. Jumlah tanaman contoh yang diamati sebanyak 25 pohon. Kelimpahan populasi kutu putih pepaya (P. marginatus) diamati langsung secara visual pada tanaman pepaya contoh (10\% dari populasi tanaman) karena kutu daun mobilitasnya sangat rendah. Pengamatan populasi dilakukan dengan interval dua minggu, dengan jumlah pengamatan sebanyak lima kali pada musim kemarau dan lima kali pada musim hujan.

Serangan kutu putih pepaya diamati secara langsung pada buah dan daun-daun tanaman contoh (10\% dari populasi tanaman) dan pengamatan ini dilakukan pada pertanaman yang sama dengan pengamatan populasi. Serangan diamati secara langsung dengan cara menghitung jumlah seluruh daun dan jumlah daun yang terserang, serta jumlah seluruh buah dan buah yang terserang yang terdapat pada setiap tanaman sampel. Persentase serangan hama kutu putih pepaya dihitung dengan cara menghitung persentase jumlah daun atau buah terserang (jumlah terserang dibagi dengan seluruh daun atau buah dikalikan 100\%). Sebagai data penunjang dicatat juga suhu dan kelembaban udara pada saat pengamatan serta kondisi curah hujan pada hari pengamatan.

Inventarisasi Tanaman Inang Kutu Putih di Sumatera Selatan. Survei tanaman inang dilakukan dengan tujuan untuk menginventarisasi tanaman inang yang diserang oleh kutu putih pepaya ( $P$. marginatus). Survei dilakukan di sentra produksi buah-buahan dataran rendah dan tinggi Sumatera Selatan. Tanaman yang dikoloni dan diserang oleh $P$. marginatus (Tabel 1),

Tabel 1. Lokasi survei tumbuhan inang Paracoccus marginatus

\begin{tabular}{llcc}
\hline No. & \multicolumn{1}{c}{ Lokasi Sentra Sayuran } & $\begin{array}{c}\text { Ketinggian Lokasi } \\
(\mathrm{m} \mathrm{dpl})\end{array}$ & $\begin{array}{c}\text { Jarak dari Kampus Inderalaya } \\
(\mathrm{km})\end{array}$ \\
\hline 1 & Gelumbang (Kab. Muara Enim) & 20 & 30 \\
2 & Tanjung Raja (Kab. OKI) & 20 & 25 \\
3 & Indralaya (Kab. Ogan Ilir) & 20 & 5 \\
4 & Muara Enim (Kab. Muara Enim) & 20 & 25 \\
5 & Kab. Banyuasin & 10 & 100 \\
6 & Pagaralam & $800-1200$ & 290 \\
\hline
\end{tabular}


diamati langsung secara visual. Survei ini dilakukan di transek sepanjang $10 \mathrm{~km}$ pada masing-masing lokasi contoh. Jika panjang satu lokasi contoh tidak mencapai $10 \mathrm{~km}$, maka garis transek dibelokkan $180^{\circ}$ transek semula. Survei dilakukan sebanyak empat kali per lokasi, yaitu dua kali pada musim hujan dan dua kali pada musim kemarau dengan selang antara satu pengamatan dengan pengamatan berikutnya satu bulan.

Analisis Data. Nilai rataan populasi nimfa dan imago, serta serangan kutu putih pada musim kemarau dan hujan dibandingkan menggunakan Chi Kuadrat. Setiap tanggal pengumpulan dan tiap jenis tanama inang dibuat tabulasi, lokasi penyebaran $P$. marginatus dipetakan.

\section{HASIL DAN PEMBAHASAN}

Populasi Kutu Putih Pepaya $P$. marginatus. Pada musim hujan, populasi imago dan nimfa $P$. marginatus paling tinggi terdapat pada pengamatan pertama yang menghasilkan populasi 144,52 ekor/tanaman pada bagian daun dan 89,20 ekor/tanaman pada bagian buah (Tabel 2). Pada pengamatan di musim hujan, perbedaan yang nyata antara populasi kutu pada daun dan buah hanya terjadi pada pengamatan pertama ketika populasi $P$. marginatus tinggi. Pada pengamatan berikutnya tidak ada perbedaan nyata antara populasi $P$. marginatuspada daun dan buah.Setelah pengamatan pertama, populasi kutu putih pepaya secara umum tidak berfluktuasi antara pengamatan satu dengan pengamatan berikutnya.

Pada musim kemarau, populasi imago dan nimfa P. marginatus pada daun dan buah tidak menunjukkan perbedaan yang nyata secara statistik (Tabel 3). Populasi kutu putih pada daun berkisar antara 8,7214,00 ekor/tanaman, sedangkan populasi kutu putih pada buah berkisar antara 4,84-8,20 ekor/tanaman. Apabila dibandingkan antara data populasi pada musim hujan (Tabel 2) dan kemarau (Tabel 3) tampaknya populasi tidak menunjukkan perbedaan yang nyata. Dari data ini didapatkan informasi baru bahwa yang selama ini kutudaun atau kutu lainnya populasinya turun akibat hentakan tetesan hujan, namun hal ini tidak terjadi pada kutu putih pepaya. Kutu putih pepaya memiliki kemampuan menempel erat pada jaringan tumbuhan inangnya dengan menggunakan stiletnya (Amarasekare et al., 2008). Tubuh kutu putih pepaya lebih kekar dibandingkan kutu lainnya. Seluruh tubuhnya diselimuti oleh lapisan lilin berwarna putih dengan embelan seperti rambut-rambut berwarna putih dengan ukuran yang pendek (Walker et al., 2003).

Tabel 2. Populasi Paracoccus marginatus pada daun dan buah pepaya musim hujan

\begin{tabular}{crrrc}
\hline \multirow{2}{*}{$\begin{array}{c}\text { Pengamatan ke- } \\
\text { (Minggu) }\end{array}$} & \multicolumn{2}{c}{ Jumlah Populasi (ekor/tanaman) } & \multicolumn{2}{c}{ Uji Kecocokan Chi Kuadrat } \\
\cline { 2 - 5 } & Daun & Buah & $X^{2}$ Statistik & $X^{2}$ Tabel $(0,05, \mathrm{db}=1)$ \\
\hline 1 & $144,52 \mathrm{~b}$ & $89,20 \mathrm{a}$ & 13,09 & 3,8145 \\
2 & $19,96 \mathrm{a}$ & $15,76 \mathrm{a}$ & 0,49 & 3,8145 \\
3 & $16,52 \mathrm{a}$ & $9,72 \mathrm{a}$ & 1,76 & 3,8145 \\
4 & $14,36 \mathrm{a}$ & $8,48 \mathrm{a}$ & 1,51 & 3,8145 \\
5 & $12,32 \mathrm{a}$ & $7,08 \mathrm{a}$ & 1,41 & 3,8145 \\
\hline
\end{tabular}

Angka yang diikuti huruf yang sama dalam satu baris menunjukkan nilai tidak berbeda nyata

Tabel 3. Populasi Paracoccus marginatus pada daun dan buah pepaya musim kemarau

\begin{tabular}{ccccc}
\hline \multirow{2}{*}{$\begin{array}{c}\text { Pengamatan ke- } \\
\text { (Minggu) }\end{array}$} & \multicolumn{2}{c}{ Jumlah Populasi (ekor/tanaman) } & \multicolumn{2}{c}{ Uji Kecocokan Chi Kuadrat } \\
\cline { 2 - 5 } & Daun & Buah & $X^{2}$ Statistik & $X^{2}$ Tabel $(0,05, \mathrm{db}=1)$ \\
\hline 1 & $8,72 \mathrm{a}$ & $4,84 \mathrm{a}$ & 1,11 & 3,8145 \\
2 & $10,72 \mathrm{a}$ & $6,72 \mathrm{a}$ & 0,91 & 3,8145 \\
3 & $14,00 \mathrm{a}$ & $8,20 \mathrm{a}$ & 1,51 & 3,8145 \\
4 & $9,56 \mathrm{a}$ & $6,20 \mathrm{a}$ & 0,71 & 3,8145 \\
5 & $13,44 \mathrm{a}$ & $7,48 \mathrm{a}$ & 1,69 & 3,8145 \\
\hline
\end{tabular}

Angka yang diikuti huruf yang sama dalam satu baris menunjukkan nilai tidak berbeda nyata 
Persentase Serangan dan Tumbuhan Inang Kutu Putih Pepaya, P. marginatus. Persentase serangan P. marginatus pada musim hujan (Tabel 4) maupun musim kemarau (Tabel 5) tidak menunjukkan perbedaan yang nyata. Serangan serangga hama umumnya berkorelasi dengan populasinya (Herlinda et al., 2005). Pada penelitian ini serangan kutu putih pepaya ini pada musim hujan mencapai 56,50\% pada daun, sedangkan pada musim kemarau mencapai 57,30\% juga pada daun. Bagian tanaman pepaya yang diserang baik daun dan buah semuanya disukai oleh kutu putih pepaya. Pada daun dan buah banyak terkandung senyawa primer yang dibutuhkan kutu putih tersebut, terutama kandungan nitrogen yang tinggi (Awmack \& Leather, 2002).

Gejala serangan kutu putih pepaya ini berupa adanya kumpulan koloni yang bergerombol yang jumlahnya dapat ratusan per koloni. Kutu putih menyerang tumbuhan inang dengan cara menusuk dan mengisap. Tumbuhan inang yang diserang menunjukkan gejala pucuk atau daun-daun muda berkeriput dan akhirnya menjadi kerdil. Kutu putih menghasilkan embun madu yang dapat ditumbuhi cendawan jelaga yang menimbulkan warna hitam pada tumbuhan inang.
Jenis Tumbuhan Inang Alternatif $\boldsymbol{P}$. marginatus. $P$. marginatus selain menyerang tanaman pepaya dapat juga menyerang labu siam, jambu biji, mangga, bunga mawar, jeruk, dan terong. Spesies tanaman inang $P$. marginatus yang ditemukan di lokasi penelitian sebanyak 12 spesies tanaman inang dan didominasi oleh dikotil. Tumbuhan inang tersebut berasal dari 11 famili, yaitu Anacardiaceae, Caricaceae, Cucurbitaceae, Euphorbiaceae, Fabaceae, Myrtaceae, Rosaceae, Rutaceae, Sapindaceae, Sapotaceae, dan Solanaceae (Tabel 6). Data penelitian ini menunjukkan bahwa kutu putih pepaya bersifat polifag yang dapat menyerang lebih dari satu famili tumbuhan inang. Hasil ini juga telah dilaporkan oleh Walker et al. (2003) yang menyatakan bahwa kutu putih pepaya tidak hanya menyerang pepaya tetapi dapat menyerang jenis dari famili lainnya, seperti tanaman kamboja, kembang sepatu, dan ubi kayu. Hama ini juga menyerang tanaman hias (Amarasekare et al., 2008). Di India dari tahun 2009-2011, P. marginatus telah menyerang 133 spesies tumbuhan dari 48 famili tumbuhan mulai dari tanaman kacang-kacangan, buahbuahan, sayuran, tanaman hias hingga tanaman obat (Sakthivel et al., 2012).

Tabel 4. Serangan Paracoccus marginatus pada daun dan buah papaya musim hujan

\begin{tabular}{ccc}
\hline $\begin{array}{c}\text { Pengamatan ke- } \\
(\text { minggu })\end{array}$ & \multicolumn{2}{c}{ Persentase serangan Paracoccus marginatus $(\%)$} \\
\cline { 2 - 3 } & Daun $(\%)$ & Buah $(\%)$ \\
\hline 1 & $57,10 \mathrm{a}$ & $55,60 \mathrm{a}$ \\
2 & $56,50 \mathrm{a}$ & $55,20 \mathrm{a}$ \\
3 & $53,90 \mathrm{a}$ & $52,60 \mathrm{a}$ \\
5 & $53,70 \mathrm{a}$ & $36,00 \mathrm{a}$ \\
\end{tabular}

Tabel 5. Serangan Paracoccus marginatus pada daun dan buah papaya musim kemarau

\begin{tabular}{ccc}
\hline $\begin{array}{c}\text { Pengamatan ke- } \\
\text { (minggu })\end{array}$ & \multicolumn{2}{c}{ Persentase serangan Paracoccus marginatus $(\%)$} \\
\cline { 2 - 3 } & Daun $(\%)$ & Buah $(\%)$ \\
\hline 1 & $56,60 \mathrm{a}$ & $35,06 \mathrm{a}$ \\
3 & $57,01 \mathrm{a}$ & $36,30 \mathrm{a}$ \\
4 & $57,30 \mathrm{a}$ & $36,60 \mathrm{a}$ \\
5 & $52,40 \mathrm{a}$ & $35,20 \mathrm{a}$ \\
\end{tabular}




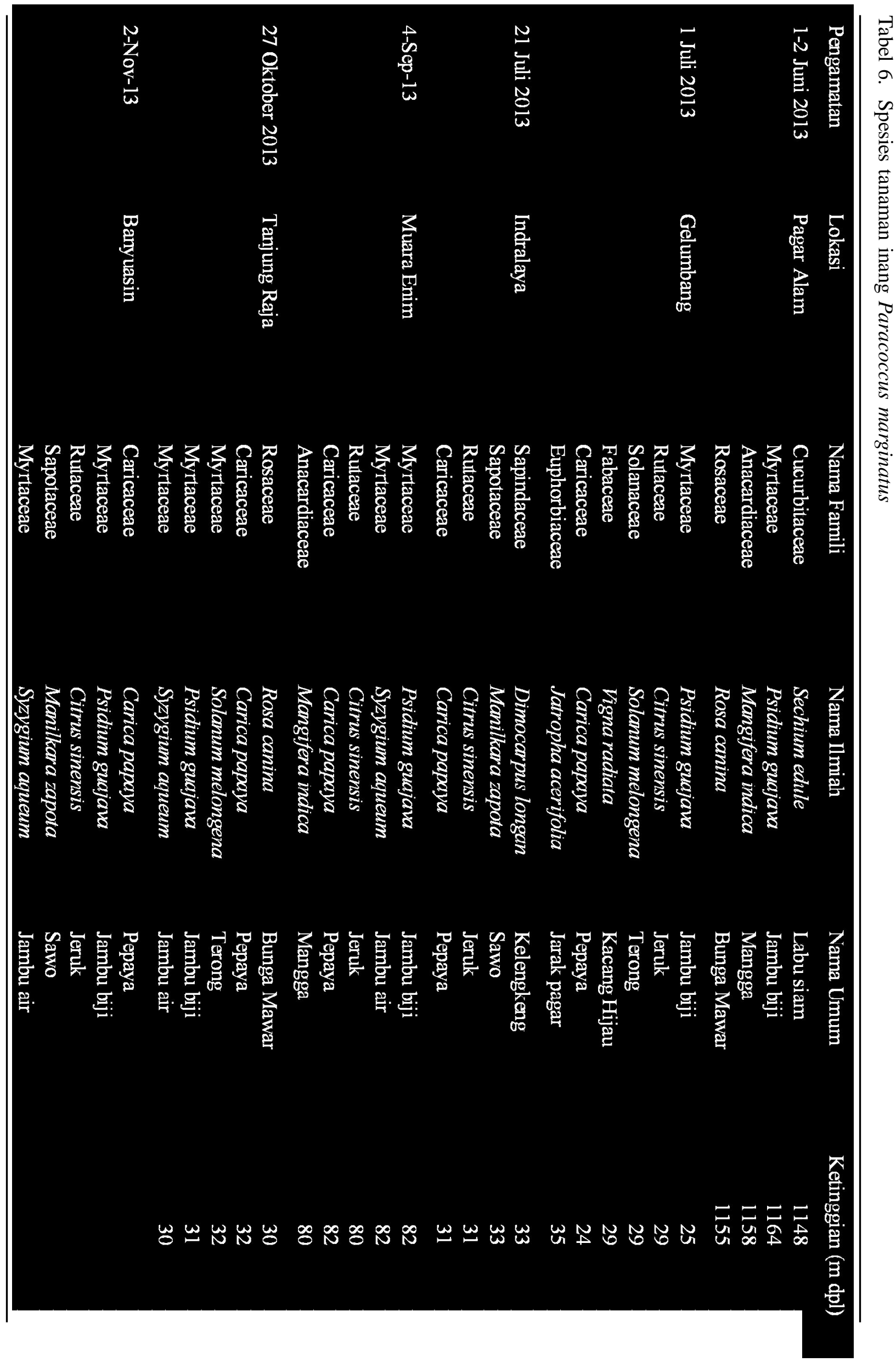




\section{SIMPULAN}

Populasi P. marginatus pada tanaman pepaya yang menyerang daun tidak berbeda nyata dengan yang menyerang buah, kecuali pada pengamatan pertama pada musim hujan. Begitu juga dengan musim tidak mempengaruhi populasi $P$. marginatus. Persentase serangan $P$. marginatus tidak dipengaruhi musim hujan atau kemarau, begitu juga lokasi serangan baik pada daun dan buah serangan tidak berbeda nyata. Spesies tanaman inang $P$. marginatus yang ditemukan di lokasi penelitian sebanyak 12 spesies tanaman inang dan didominasi oleh dikotil. Tumbuhan inang tersebut berasal dari 11 famili, yaitu Anacardiaceae, Caricaceae, Cucurbitaceae, Euphorbiaceae, Fabaceae, Myrtaceae, Rosaceae, Rutaceae, Sapindaceae, Sapotaceae, dan Solanaceae.

\section{SANWACANA}

Penelitian ini bagian dari Penelitian Hibah Bersaing yang dibiayai oleh Direktorat Jenderal Pendidikan Tinggi, Kementerian Pendidikan dan Kebudayaan Tahun Anggaran 2013 yang diketua oleh Rosdah Thalib.

\section{DAFTAR PUSTAKA}

Amarasekare KG, Mannion CM, Osborne LS, \& Epsky ND. 2008. Life history of Paracoccus marginatus (Hemiptera: Pseudococcidae) on four host plant species under laboratory conditions. Environ. Entomol. 37(3): 630-635.

Awmack CS \& Leather SR. 2002. Host plant quality and fecundity in herbivorous insect. Annu. Reu. Entomol. 47: 817-844.
Friamsa N. 2009. Biologi dan Statistik Demografi Kutu Putih Pepaya, Paracoccus marginatus Williams \& Granara de Willink (Hemiptera: Pseudococcidae) pada Tanaman Pepaya (Carica papaya L). Departemen Proteksi Tanaman, Institut Pertanian Bogor, Bogor.

Herlinda S, Rosalina LP, Pujiastuti Y, Sodikin E, \& Rauf A. 2005. Populasi dan serangan Liriomyza sativae (Blanchard) (Diptera: Agromyzidae), serta potensi parasitoidnya pada pertanaman ketimun. J. HPT Tropika 5(2): 73-81.

Muniappan R, Shepard BM, Watson GW, Carner GR, Sartiami D, Rauf A, \& Hammig MD. 2008. First Report of the Papaya Mealybug, Paracoccus marginatus (Hemiptera: Pseudococcidae), in Indonesia and India. Journal of Agricultural and Urban Entomology 25(1): 37-40.

Rauf A. 2009. Pest Risk Analysis: Paracoccus marginatus. Departemen Proteksi Tanaman. Fakultas Pertanian IPB, Bogor.

Sakthivel P, Karuppuchamy P, Kalyanasundaram M, \& Srinivasan T. 2012. Host plants of invasive papaya mealybug, Paracoccus marginatus (Williams and Granara de Willink) in Tamil Nadu. Madras Agric. J. 99: 615-61.

Walker A, Hoy M, \& Meyerdirk D. 2003. Papaya mealybug (Paracoccus marginatus Williams and Granada de Willink (Insecta: Hemiptera: Pseudococcidae). Featured creatures. Institut of Food and Agricultural Sciences, University of Florida, Gainesville. 